\title{
Pragmatic Randomised Controlled Trial of an Exercise Programme to Improve Wellbeing Outcomes in Women with Depression: Findings from the Qualitative Component
}

\author{
Elizabeth Khalil, Patrick Callaghan, Tim Carter, Ioannis Morres \\ School of Nursing, Midwifery and Physiotherapy, University of Nottingham, Nottingham, UK \\ Email: Elizabeth.Khalil@nottingham.ac.uk
}

Received July 19 ${ }^{\text {th }}$, 2012; revised August 19 ${ }^{\text {th }}$ 2012; accepted September $23^{\text {rd }}, 2012$

\begin{abstract}
This paper reports the qualitative component from a pragmatic randomized controlled trial (PRCT), the quantitative component is reported in Callaghan, Khalil, Morres and Carter (2011). Exercise may be effective in treating depression, but trials testing its effect in depressed women are rare. Our previous research found that standard exercise programmes, prescribed by General Practitioners and based on national guidelines of intensity levels thought to produce health benefits, are not suitable for this group, as they find them discouraging and lonely, with many dropping out very early on. Exercise that is matched to participants' preferred intensity improves mental health outcomes and attrition rates. Our aim was to develop such a programme. This study addressed the question: does mentored exercise of preferred intensity lead to better psychological, physiological and social wellbeing outcomes and improved adherence rates when compared with exercise of prescribed intensity in 38 depressed women? Focus groups were conducted with participants from both arms of the study, to explore their experience of the exercise programme and to gather information that might help to explain the quantitative outcomes, a technique recommended by previous researchers conducting pragmatic trials. Women in the experimental programme experienced a statistically significant improvement in their mood, physical health, sense of wellbeing, self-esteem and quality of life. They reported achieving these gains via a positive experience which encouraged continued attendance. In contrast, women who received the "exercise as usual" programme experienced no significant benefits, were less likely to continue attending, and markedly less enthusiastic.
\end{abstract}

Keywords: Depression; Exercise; Mental Health; Pragmatic Randomised Controlled Trial; Wellbeing; Women

\section{Introduction}

\section{The Link between Physical and Mental Illness}

Health is "a state of complete physical, mental, and social well-being and not merely the absence of disease, or infirmity" (World Health Organisation, 2007). Within the notion of global wellbeing, there are physical, psychological and social constructs, and between them is a complex interplay (Department of Health [DoH], 2006; Mental Health Foundation, 2006; Seymour, 2003).

People with mental health problems are more likely to experience physical ill health than the rest of the population, they have high levels of physical morbidity and mortality (Nocon, 2004; Phelan, Stradins, \& Morrison, 2001), being mentally ill increases a person's risk of ill-health and may shorten their life by 10 years (Robson \& Gray, 2007).

Depression impacts on a range of physical health outcomes; it is associated with asthma, arthritis and diabetes (Turner \& Kelly, 2000), is a risk factor for stroke (Ostir, Markides, Peek, \& Goodwin, 2001) and increases the risk of heart disease by four times (Hippisley-Cox, 1998). Depression occurs in between $5 \%$ and $10 \%$ of people seeking primary care in the UK and is expected to be the second most common cause of disability worldwide; rates for women are double that of men (Richardson, Faulkner, McDevitt, Skrinar, Hutchinson, \& Piette,
2005).

\section{The Health Benefits of Exercise}

There is consistent evidence that physical activity is beneficial across the range of physiological, psychological, and social outcomes that comprise global well-being (Thompson, 1994). Encouraging regular exercise represents an opportunity to tackle many of the inter-related health problems facing individuals with a mental disorder, such as low self-esteem, obesity, elevated blood pressure (DoH, 2004). Exercise can also help people to function better through alleviation of stress and improved sleep (Kubitz, Landers, Petruzello, \& Han, 1996; Sherill, Kotchou, \& Quan, 1998; Youngstedt, O’Connor, \& Dishman, 1997), improved mood (Biddle, 2000) and self-perception (Fox, 2000).

\section{The Health Benefits of Exercise in Depression}

In addition to improving general health and wellbeing, physical exercise has been shown to be effective as a treatment of mild, moderate and severe clinical depression, and can be as effective as psychotherapy or medication in the long term (Barbui, Butler, Cipriani, Geddes, \& Hatcher, 2007; Biddle, 2000; Blumenthal, Babyak, Moore, Craighead, Herman, \& Katri, 1999; Callaghan, 2004; Craft \& Landers, 1998; Scully, 
Kremer, Meade, Graham, \& Dudgeon, 1998). Both the Lawlor and Hopker (2001) and Cochrane (2009) systematic reviews of the effect of exercise on depression reported that exercise improves depressive symptoms. Exercise can also reduce the risk of suffering clinical depression (Paffenberger, Lee, \& Leung, 1994; Dunn, Trivedi, \& O’Neal, 2001).

These benefits are now recognized in official national guidance on health care, and in particular for depressed individuals, for example, NICE (2004) recommended that sufferers of mild depression of all ages are advised of the benefits of participating in an exercise programme of a moderate level three times a week. In "Up and Running" (2004) the Mental Health Foundation review the evidence and present a strong case for exercise referral as "inexpensive, effective, and having coincidental benefits", and as Mutrie (2002) points out, unlike drug therapy, exercise has few negative side effects.

Despite the fact that consultation rates are three to four times higher than for the general population (Seymour, 2003), people with mental illness are less likely to be offered health promotion interventions, or exercise prescriptions (Cohen \& Hove 2001; Friedli \& Dardis, 2002). In 2004, the Mental Health Foundation reported that $42 \%$ of GPs have access to an exercise referral scheme, and of the GPs surveyed only 5\% used exercise as one of their top three front-line treatments for depression (MHF, 2004). Less than half of the GPs surveyed felt exercise was an effective treatment for depression. Moreover, when exercise interventions are offered, they are often of little use to the client group. Women living with depression in the community regard the mainstream exercise regimes prescribed by their GP as a negative experience (Owen \& Khalil, 2006). While the benefits of exercise to physical health are widely known, the benefits to mental health are still less well understood and accepted (MHF, 2004). On the whole exercise appears to be a neglected intervention in mental health care. There is little or no mention of exercise as a treatment option in most standard mental health/illness texts or reports published by authoritative groups in mental health (Callaghan, 2004). There are, however, notable exceptions, The National Quality Assurance Framework for Exercise [NQAFE] (Department of Health, 2001) acknowledges the strong causal evidence for the impact of exercise on mental health and offers detailed guidance to mental health workers interested in referring patients to exercise referral programmes.

There is a clear need for an intervention comprising physical activity that is accessible and appropriate to people with depression in particular for whom the evidence suggests exercise is a sound first-line treatment option; it is less expensive to deliver than many alternatives; promotes social inclusion; is popular; has few side effects; and the mechanism for delivery in a primary care context already exists in the form of exercise referral schemes (MHF, 2004).

Whilst a growing body of research has focused on the physical health problems of adults with mental illness; less is known about acceptable and appropriate practice regarding the provision of lifestyle interventions to this group (Bradshaw, 2005). The Cochrane (2005) systematic review of 25 depression trials found little evidence about the most effective type of exercise, or how effective it can be. Only six trials sampled clinical populations.

Several factors emerge from the literature and the research teams' previous work as vital to the design and delivery of such an intervention to depressed individuals. "There is emerging evidence that people with serious mental illness can be more physically active if interventions and lifestyle programmes are tailored to overcome the neurological, behavioural and social deficits associated with serious mental illness" (Robson \& Gray, 2007). "Exercise therapy needs to be delivered in such a way that support for the patient is maximized. Embarking on behavior change is not easy, especially for a population with motivation difficulties, and it is more likely to be successful when that change is supported by well-trained specialist staff, able to devote their time and attention to helping people with their programme" (MHF, 2004).

\section{Designing an Exercise Programme for Depressed People}

When testing the effect of exercise on mental health outcomes among healthy people, researchers often use intervenetions based on national guidelines of intensity levels thought to produce health benefits (McGeorge, 2004). Notwithstanding the benefits of exercise, national and international studies show that many people with mental health problems do not engage in physical activity, and struggle to maintain the prescribed intensity, as result, high attrition rates are reported (Morgan, 2001). Our previous research found that standard GP prescribed exercise programmes, based on national guidelines of intensity levels thought to produce health benefits, are not suitable for this group, as they find them discouraging and lonely, with many dropping out very early on (Owen \& Khalil, 2006). Exercise that is matched to participants' preferred intensity improves mental health outcomes and improves attrition rates (Callaghan \& Norman, 2004). Ideally people need to exercise with sufficient intensity for 20 - 30 minutes three to five times a week to experience health benefits (British Heart Foundation, 2003; Callaghan, 2004; DoH, 2004; Ekkekakis, Hall, VanLanduyt, \& Petruzello, 2000). Benefits are observed regardless of age or socioeconomic status (DoH, 2004). Our earlier work suggests that tailored interventions supplemented with motivetional support may increase self-esteem and overall quality of life, and reduce exercise attrition rates (Callaghan \& Norman 2000; Callaghan, Eves, Norman, Cheung, \& Chang, 2002). In the scoping study that preceded this trial, Owen and Khalil (2006) found that women living with depression in the community expressed preferences for low-intensity exercise of particular activities in particular environments. Group projects were cited as preferable, with peers (of similar physical and mental health status); low impact activities such as swimming and walking were preferred. Rhythmic, aerobic forms of exercise, such as brisk walking, jogging, swimming, or dancing are most consistently effective in achieving mental health benefits (DoH, 2004). All of these factors were taken into consideration when designing our programme to be emotionally supportive, friendly, sensitive and responsive to the specific needs of this group, and featuring low impact rhythmic exercise (brisk walking) within a facilitated group of peers, led by specialist staff.

\section{Rationale and Research Question}

Improving the physical health of people with mental illness is a national priority (DoH, 1999, 2004, 2006). Physical health care for women living with depression, is an area that has been flagged up by the Department of Health in its national policy to address the disparities in providing services to mentally ill 
women (DoH, 2003).

In this study we addressed the question: does mentored exercise of a preferred intensity lead to better psychological, physiological and social wellbeing outcomes and improved adherence rates when compared with exercise of prescribed intensity?

\section{Research Hypotheses}

From the PRCT encompassing this qualitative component:

$\mathrm{H}_{1}=$ A tailored exercise intervention will lead to better psychological, physiological and social wellbeing outcomes when compared with an intervention based on national recommendations.

$\mathrm{H}_{2}=$ Women assigned the tailored programme will attend a greater number of sessions than women assigned the standard prescribed programme of exercise.

\section{Method}

This paper focuses on the qualitative component of the Pragmatic Randomised Controlled Trial (PRCT). Further detail concerning design and delivery of the trial may be found in Callaghan, Khalil and Morres (2011). Both the experimental and control programmes were fully manualised, and a protocol devised for both the motivational interviewing and healthy lifestyles components. This ensured transparency of approach, replicability and minimizes researcher effects in delivery.

There were a total of seven programmes run, with approximately four women exercising together in each, at three different sites-local authority leisure centres-in Nottinghamshire. Figure 1 outlines the control and experimental arms of the study.

\section{Design}

The exercise programme was evaluated in a "pragmatic randomised controlled trial" (Hotopf, 2002). This design is especially suited to encompassing a complex intervention such as our programme and informing everyday practice with evidence. In addition, the women we aimed to improve outcomes for we have defined very broadly as "living with depression", as it is the presentation, and not specific diagnoses, that leads to specific challenges for service providers. The pragmatic randomised controlled trial (PRCT) is particularly suited to reflecting the heterogeneity of patients encountered in clinical practice and keeping exclusion criteria to a minimum (Hotopf, 2002). This was crucial as our aim was to target a programme to the women presenting to GPs as "depressed" in functional terms with the aim of improving their daily situation. A mixed method approach was employed in data collection, analysis and interpretation, using both quantitative and qualitative methods and measures. In order to meet our stated research objectives a positivistic approach was essential. A battery of outcome measures was devised and piloted by the project team, advised by the steering group, to capture change across a representative selection of the spectrum of physical, psychological and social components of wellbeing. However, there have been calls from researchers and mental health bodies working in this area for more qualitative data collection and analysis to unpack the nature of why exercise seems a preferred treatment choice, and what makes a helpful exercise programme (Oakley, Strange, Bonell, Allen, \& Stephenson, 2006), and to "convey the richness

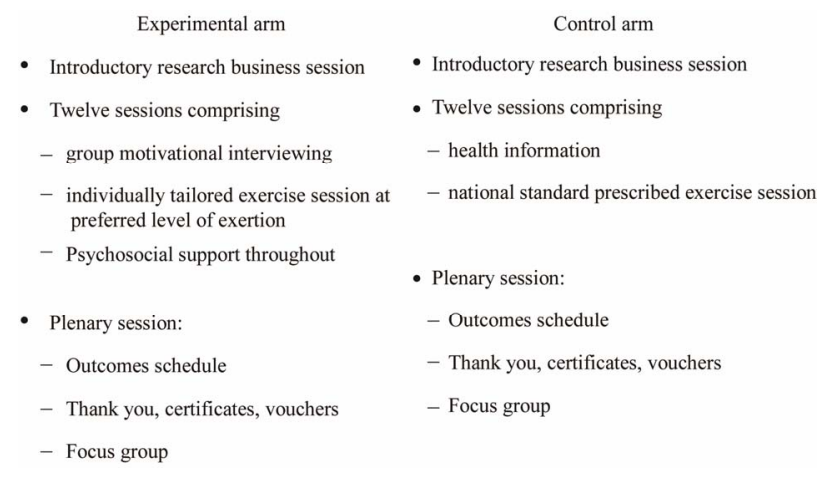

Figure 1.

Design of the study.

of experience reported by those who employ exercise as a recovery strategy" (MHF, 2004). It is rare to find studies investigating the role of exercise on health that use qualitative research methods (Callaghan, 2004), yet they allow researchers to study intensively the participants' experiences. For these reasons a substantive qualitative strand was included in the study design. Moreover, the nature of a pragmatic controlled trial means that it is appropriate for a real world intervention such as this, yet while such a design will reveal whether the intervenetion is helpful, it will not necessarily be clear how the intervention achieves this, as variables are not subject to such stringent control as in a traditional RCT. Again, qualitative data collection in the form of focus groups at the end of each programme, but also in the form of ongoing field notes throughout each programme are essential in documenting and exploring the reasons why exercise may be helpful.

\section{Promotion, Recruitment and Sampling}

The project team set up a project website, carefully piloted and targeted at the sample group, with an automated system for acquiring more information about the project. A dedicated telephone line with a named member of the project team, a female, was also provided. A poster/flyer was designed to circulate widely, again carefully targeted to appeal to the intended audience.

The project team sent information letters to primary (GP surgeries in both PCTs) and secondary services (Nottinghamshire Healthcare NHS Trust Mental Health Services), detailing the study and inviting clinicians to assist us in identifying potential participants. Those services agreeing to engage with us received a pack containing a poster to display where potential participants could see it, a set of flyers to hand to potential participants, and a flow chart to guide each clinician through the inclusion criteria. Clinicians were requested to hand the flyer out to every consecutive potential participant (to maximise opportunity for interested women to participate and minimise selection bias), having worked through the inclusion criteria. In addition our collaborating service user group "Making Waves" and the East Midlands hub of the Mental Health Research Network publicised the programme among its members and relevant independent and voluntary sector organisations and contacts. Furthermore, we promoted our study in the local media and on the University of Nottingham web pages.

Consenting participants were randomly allocated prior to inclusion into the intervention or control arm at a gym appropri- 
ate to their home address via a dedicated central allocation and randomisation system, by a research professional unconnected to the study.

\section{Participants}

38 women participated in the study, 19 in each arm. Women were included if they were being monitored by, or receiving treatment for depression from any primary or secondary mental health service, aged 45 - 65 (age at first session of programme), living in the community and resident within Nottinghamshire as indicated by postcode. Participants were excluded if, at the time of the study, they were unable to participate on account of any injury or physical health problem.

\section{Procedure}

The qualitative component to the study took the form of focus groups with participants from the intervention and active comparator arms of the study; moreover field notes were collected throughout every session of each programme, to document and explore the journey that the women made. Participants often added input to these field notes, mentioning aspects of their journey that they felt were important to the experience. A focus group lasting approximately 45 minutes to an hour was conducted at the close of each programme, three to five women participated in each group, which was facilitated by the same researcher in each instance. The focus group topic guide (Table 1), was informed by the literature base and the service user views from the preceding scoping study (Owen \& Khalil, 2006), and advised by the project steering group.

\section{Ethical Approvals and Adoptions}

The study was adopted by the Mental Health Research Network (East Midlands Hub), and is registered with the US National Institutes of Health clinical trials database

(https://register.clinicaltrials.gov). It had R \& D approval from Nottinghamshire Healthcare NHS Trust, Nottingham City Primary Care Trust and Nottinghamshire County Teaching Primary Care Trust. The study received a favourable ethical opinion from Derbyshire Research Ethics Committee via the National Research Ethics Service (ref. 07/H0401/110).

\section{Results}

This paper focuses on the qualitative component of the Pragmatic Randomised Controlled Trial (PRCT). From the quantita-

Table 1.

Focus group topic guide.

\footnotetext{
1) What was your experience of the exercise programme?

i) What was positive or rewarding?

ii) And negative or discouraging?

2) How has participation in the programme affected your mood?

3) How has participation in the programme affected your physical health?

4) Do you feel generally better, worse or the same for having taken part?

5) Please comment on the length of the sessions; too long; too short; about right?

6) If you could continue to do exercise sessions like this on a regular basis, would you?

7) What might be the barriers to you doing exercise sessions like this on a regular basis?

8) Any other comments or questions?
}

tive component, the battery of outcome measures devised to capture change across a representative selection of the physical, psychological and social components of wellbeing revealed a statistically significant improvement in mood, physical health, sense of wellbeing, self-esteem and quality of life in experimental arm participants. The intervention group attended a greater number of exercise sessions (8 $(66 \%)$ out of a possible 12 sessions) than the control group (6 (50\%) out of a possible 12 sessions), giving a mean difference of 2.3 sessions (95\% CI: 0.3 to 4.8 ). Further detail concerning quantitative outcomes of the trial may be found in Callaghan, Khalil and Morres (2011).

\section{Transcript Analysis}

Framework analysis (Lacey \& Lacey, 2001) was used to analyse the focus group data and field notes. This thematic analysis technique was chosen because it allows for the inclusion of a priori (previously identified as relevant) and emergent concepts (e.g. unforeseen views or experiences from the participants). This method of analysis is particularly suited to health services research as it provides "systematic and visible stages to the analysis process, so that funders and others can be clear about the stages by which the results have been obtained from the data" (Lacey \& Lacey, 2001). The topic schedule formed the basis for the core themes in the thematic framework. A total of seven focus groups were conducted, and seven sets of field notes collected, one for each exercise programme.

\section{Conceptual Framework Findings}

The findings are presented in Table 2 in a conceptual framework, organised as follows:

Core theme 10: Your experience of the programme.

Core theme 11: Effect on your mood and general wellbeing.

Core theme 12: Effect on your physical health.

Core theme 13: What should we keep and what could we improve?

Core theme 14: Would you continue?

Core theme 15: Barriers to exercise.

\section{Summary of the Findings}

The women in the experimental arm reported a positive experience of the programme, and also stated that they had not encountered anything negative in the programme. In contrast, the control arm reported some negative experiences of their programme, and did not report having had a positive experience. The experimental arm reported that the positives were feeling safe and supported, and feeling motivated and encouraged, and feeling part of a group. The control arm did not report any of these positives. The experimental arm reported a positive effect on their mood, or "feeling better". The control arm made no reports of benefit to mood. Whereas some of the experimental arm participants reported physical improvement, the control arm reported physical discomfort. On the topic of what was good about the programme, and what could be improved, the experimental arm overwhelmingly stated being in a supportive group as a good feature. Some women reported that they would like the opportunity to exercise for a little longer, or try different forms of exercise, as they progressed within the programme. When asked if they would continue on the programme the majority of women in the experimental arm said yes, whereas the control arm stated that they would not, or that it would be 
Table 2.

Conceptual framework of focus group findings.

\begin{tabular}{|c|c|c|}
\hline Study arm & A priori themes & Emergent themes \\
\hline Experimental & $\begin{array}{l}\text { 10.1 Positive experience } \\
\text { 10.2 Negative experience (absence of) }\end{array}$ & $\begin{array}{l}\text { 10.3 Feeling safe, no worries } \\
\text { 10.4 Motivation, encouragement, and sticking to it. }\end{array}$ \\
\hline Control & 10.2 Negative experience & \\
\hline Experimental & $\begin{array}{l}\text { 11.1 Positive effect on mood } \\
\text { 11.3 I feel better }\end{array}$ & \\
\hline Control & $\begin{array}{l}\text { 11.2 No or negative effect on mood } \\
\text { 11.3 I feel better } \\
\text { 11.4 I feel worse }\end{array}$ & \\
\hline Experimental & $\begin{array}{l}\text { 12.1 Positive effect on physical health } \\
\text { 12.3 Physical confidence }\end{array}$ & 12.4 Pacing myself \\
\hline Control & $\begin{array}{l}\text { 12.1 Positive effect } \\
\text { 12.2 No or negative effect } \\
\text { 12.3 Physical confidence }\end{array}$ & \\
\hline Experimental & $13.1 \mathrm{I}$ like being in a group & $\begin{array}{l}\text { 13.2 Length of sessions (just right) } \\
\text { 13.2 Length of sessions (would like longer) } \\
\text { 13.3 Exercise type and environment (just right) } \\
\text { 13.3 Exercise type and environment (would like to branch out) } \\
\text { 13.3 Exercise type and environment (prefer the quiet gym) } \\
\text { 13.4 Feeling secure }\end{array}$ \\
\hline Control & & $\begin{array}{l}\text { 13.2 Length of sessions (too long) } \\
\text { 13.2 Length of sessions (I couldn't control it) } \\
\text { 13.3 Exercise type and environment (would like to branch out) }\end{array}$ \\
\hline Experimental & & 14.1 I want to continue \\
\hline Control & & $\begin{array}{l}\text { 14.2 I do not want to continue } \\
\text { 14.2 I won't manage to continue }\end{array}$ \\
\hline Experimental & & $\begin{array}{l}\text { 15.1 Exercise environment ( mirrors on the wall, mixed genders) } \\
\text { 15.2 Exercise modality (no variety) } \\
\text { 15.3 Motivation and logistics (time, money, planning) } \\
\text { 15.4 Other's attitudes (justifying time, controlling partners) }\end{array}$ \\
\hline Control & & 15.3 Motivation and logistics (money) \\
\hline
\end{tabular}

unlikely. In terms of barriers to exercise, the most often stated obstacles were doing it alone, cost, prioritising the time, and other's attitudes.

\section{Discussion}

This qualitative component of a larger PRCT study aimed to explore the participants' experiences of a tailored programme of low effort physical activity and psychosocial support on global well-being in a community-based sample of women living with depression, to help in interpreting the quantitative findings of the PRCT study, but also because there is a paucity of qualitative studies of exercise as a treatment for depression (MHF, 2004).

Adherence rates for middle-aged depressed women are not well known, previous qualitative research reports low levels of attendance in this group (Owen \& Khalil, 2006). The experimental arm participants attended significantly more exercise sessions than the control arm women, in the focus groups they made it clear that they felt the rewarding nature of the experience had encouraged them to attend, when perhaps they may previously have failed to do so. It is clearly important that exercise programmes intended for delivery to people with mental health problems are specifically designed to be acceptable and accessible to this group. Existing research literature concurs with these findings of this study, that where exercise interven- tions are specifically tailored to be acceptable to people with mental health problems "contrary to common opinion, adherence... is at least similar to other forms of treatment. In one study where physical activity was offered as part of psychiatric services, adherence was comparable to that of the general population" (DoH, 2004).

Themes evident in the focus group data from the experimental arm validated the design and delivery of the specially designed exercise programme:

My experience of the exercise programme was positive and rewarding.

I feel positive and rewarded in the exercise and it's coping with the illness isn't it, instead of just sitting and moping in that rut.

Participation in the programme has had a beneficial effect on my mood.

Participation in the programme has had a beneficial effect on my physical health.

I feel more confident in my physical self and my emotional self. I do think it's helped with my mood.

I feel generally better for having taken part.

I feel energised.

If I could continue to do exercise sessions like this on a regular basis I would.

Yes!

Existing literature (Biddle, 2001) indicates that the psycho- 
logical benefits of exercise, outcomes such as "feeling better" and enjoyment, assist long-term motivation. The women in the tailored programme felt "better" and enjoyed their exercise experience, this is important in helping them to maintain a longer term exercise routine and stay motivated. Many of the women in our study had not previously explored exercise as a treatment or adjunct to treatment, and were delighted to discover the benefits. We can conclude that carefully targeted programmes that maximize psychological benefits make exercise a sustainable treatment choice. The evidence base is unanimous in the opinion that currently "exercise is seldom recognized by mainstream mental health services as an effective intervention in the care and treatment of mental health problems" (Callaghan, 2004; MHF, 2004). Exercise promotion needs to be part of every care package (and tailored specifically to this group based on available evidence and user input). Robson and Gray (2007) suggest that this process should begin when the service user first comes into contact with mental health services. The Chief Nursing Officer's Review of Mental Health Nursing recommends that MHNs "actively engage in health promotion strategies... for example by encouraging physical exercise" (DoH, 2006), Gray and Robson (2007) also point out the opportunity for MHNs to play a significant role in this arena. Some of the women in this study reported being offered exercise on prescription as a method of weight maintenance (weight gain is a side-effect of many anti-depressants), but not as a treatment of depression. The majority of GPs do not currently prescribe exercise as a treatment for depression or recognize its value (Mental Health Foundation, 2004). The Mental Health Foundation (2004) recommend that GPs with access to exercise referral schemes should offer all patients presenting with mild or moderate depression the opportunity for referral to that scheme as part of their treatment plan. Many of the women who participated in the study had used anti-depressant medication and been dismayed by the unpleasant side-effects. Conversely, no participants reported unpleasant side-effects as a result of engaging in exercise, other than occasional reports of mild aches from using dormant muscles, yet positive benefits were experienced.

Themes evident in the focus group data revealed four key elements in designing and delivering an appropriate intervenetion to this group:

1) The facilitated group nature of the sessions was vital:

I' $m$ really pleased and proud of what I did, and I wouldn't have done it without the fact that I was in a group, and the encouragement and bonding of the group and everyone in it was really helpful, all of us chatting and going in together.

2) The opportunity to explore the exercise environment was invaluable, reduced anxiety, and increased comfort:

They look to be the same age as us!

3) My significant others' negative attitudes to me exercising is an obstacle to belief in change:

What do you want to do that for?

4) Money and scheduling might be the barriers to me doing exercise sessions like this on a regular basis.

Our findings reveal that the social aspect of an exercise programme is valued by women with depression. However, as the government report "Five a Day" points out "little is known about the potential of physical activity to alleviate social exclusion or to enhance social outcomes; it is likely that the impact... is greater than the limited evidence base suggests" (DoH, 2004). Clearly further research exploring the potential social benefits and how these could be maximized is required. As "Five a Day" (DoH, 2004) suggests, there is a potential for physical activity programmes to be utilized as part of a wider ranging strategy to tackle issues such as social exclusion. The majority of participants reported surprise at discovering that other people exercising were "the same as us", the experience was seen as normalizing, as opposed to stigmatizing as so many gym users "are the same as us" it was seen as a normalising experience, rather than stigmatizing, which was their experience of other treatments such as medication and talking therapy. Affordability was cited as a barrier to regular exercise, by women considering funding the treatment themselves, but in fact, exercise offered on script is a very affordable choice for commissioners (MHF, 2004).

Participants highlighted the importance of belief when they reported that they felt that their families' attitude to their exercise regime could influence their experience, and their potential for benefit. Belief in change appears to play a central role in the benefits derived from exercise and in maintenance of a life-time routine. It seems paramount therefore that participants have adequate emotional support, especially in the initial stages of establishing an exercise habit, and equipped with strategies for overcoming obstacles and maintaining the changes in their lifestyle. One of the most fundamental ways in which this study supported the participants was to make the opportunity to explore the exercise environment and physically escort participants over the threshold (it had been suggested in the previous pilot study that this may be an area of real challenge to the participants). Women reported this aspect of the design as being invaluable to them in terms of reducing their anxiety and promoting belief that change was possible. Support of this type was gradually withdrawn as the experimental groups established their own support mechanisms and grew in confidence. This is a good example of a very specific way in which a programme for this client group may need to be structured to facilitate attendance in the early stages of establishing an exercise routine.

\section{Conclusion}

A tailored exercise programme demonstrated significant benefit across a range of psychological, social and physical outcomes constituting "health in women living with depression". The women achieved these gains via a positive, comfortable experience. The positive nature of the experience encouraged regular attendance. Delivering an intervention informed by service users and responsive to them ensured the success of the programme.

\section{Recommendations}

Several areas key to improving the wellbeing of women living with depression through exercise participation coupled with psychosocial support have been identified in this study. Recommendations are made regarding these areas, encompassing general principles for delivery and design of exercise intervenetions and for further research.

\section{Provision of Exercise Interventions for People with Mental Illness}

All GPs should offer women presenting with mild or moderate depression the opportunity for referral to exercise pro- 
grammes tailored to their needs.

It needs to be clear to the target group that the exercise offered is specifically tailored to their needs.

Prescribed exercise programmes need to focus on improving, and measuring improvement in, health and social care outcomes.

Provide primary care practitioners, MHNs and local authority leisure centre staff with basic training and manualised guidelines for recruiting and supporting depressed women in exercise activity, continued attendance without dropping out, and return to exercise after periods of crisis.

\section{Design of Exercise Programmes}

Exercise programmes should include service user involvement in design and delivery, and systematically collect and respond to feedback from users.

Exercise programmes designed for women living with depression need to be structured to facilitate attendance in the early stages of establishing an exercise routine.

Exercise programmes must pay attention to the value of exercise as a normalizing experience that promotes social inclusion, focusing on group exercise in a supportive friendly environment.

Exercise programmes should be evaluated against a range of wellbeing outcomes with special reference to continued attendance as a discrete measure of perceived benefit.

\section{Research on Exercise and Mental Health}

Further qualitative research exploring what makes for an acceptable, accessible exercise programme is needed. A longitudinal study evaluating the longevity of lifestyle change and benefit, as well as issues around returning to exercise following a crisis is recommended.

Further research focusing on how the social mechanisms of support, interaction and affiliation are linked to exercise adherence is needed.

There is a need also for more focus on how the social mechanisms of support, interaction and affiliation might work within exercise programmes.

\section{Acknowledgements}

Thanks to The Burdett Trust for Nursing for funding this research (Grant ref. 293/350). The Mental Health Research Network adopted this study; many thanks to the East Midlands Hub for all their assistance. The authors would also like to thank everyone at the Middle Street Resource Centre for being so supportive and enthusiastic about the research.

\section{REFERENCES}

Alaoui-Ismaïli, O., Robin, O., Rada, H., Dittmar, A., Vernet-Maury, Barbui, C., Butler, R., Cipriani, A., Geddes, J., \& Hatcher, S. (2007). Depression in adults (drugs and other physical treatments). BMJ Clinical Evidence, 6, 1-27.

Biddle, S. J. H. (2000). Emotion, mood and physical activity. In: S. J. H. Biddle, K. R. Fox, \& S. H. Boutcher (Eds.), Physical activity and psychological well-being (pp. 63-87). London: Routledge.

Blumenthal, J. A., Babyak, M. A., Moore, K. A., Craighead, E., Herman, S., Khatri, P. et al. (1999). Effects of exercise training on older patients with major depression. Archives of Internal Medicine, 159, 2349-2356. doi:10.1001/archinte.159.19.2349
British Heart Foundation (2003). BHF coronary heart disease statistics. London: British Heart Foundation.

Callaghan, P., \& Norman, P. (2000). Motivations and predictors of exercise in Chinese high school children. International Journal of Behavioral Medicine, 7, 23-24.

Callaghan, P., Eves, F. F., Norman, P., Cheung, Y. L., \& Chang, A. M. (2002). Applying the transtheoretical model of change to exercise in young Chinese people. British Journal of Health Psychology, 7, 267282. doi:10.1348/135910702760213670

Callaghan, P., \& Norman, P. (2004). A prospective evaluation of the theory of planned behaviour (TPB) and the transtheoretcial model of change (TTM) on exercise in young people. Psychology and Health, 19, 29-30.

Callaghan, P. (2004). Exercise: A neglected intervention in mental health care? Journal of Psychiatric and Mental Health Nursing, 11, 476-483. doi:10.1111/j.1365-2850.2004.00751.x

Callaghan, P., Khalil, E., Morres, I., \& Carter, T. (2011). Pragmatic randomised controlled trial of preferred intensity exercise in women living with depression. BMC Public Health, 11, 465-472. doi:10.1186/1471-2458-11-465

Cohen, A., \& Hove, M. (2001). Physical health of the severe and enduring mentally ill: A training pack for GP educators. London: Sainsbury Centre for Mental Health.

Craft, L. L., \& Landers, D. M. (1998). The effect of exercise on clinical depression and depression resulting from mental illness: A metaanalysis. Journal of Sport and Exercise Psychology, 20, 339-357.

Department of Health (1999). The national service framework for mental health. London: The Stationary Office.

Department of Health (2001). The national quality assurance framework for exercise. London: Department of Health.

Department of Health (2003). Womens' mental health: Into the mainstream. Strategic development of mental health care for women. London: The Stationary Office.

Department of Health (2004). At least five a week: Evidence on the impact of physical activity and its relationship to health. A report from the Chief Medical Officer. London: HMSO.

Department of Health (2004). Choosing health: Making healthier choices easier. London: HMSO.

Department of Health (2006). From values to action: The chief nursing officer's review of mental health nursing. London: HMSO.

Dunn, A. L., Trivedi, M. H., \& O’Neal, H. A. (2001). Physical activity dose-response effects on outcomes of depression and anxiety. Medicine and Science in Sports and Exercise, 33, 87-597. doi:10.1097/00005768-200106001-00027

Ekkekakis, P., Hall, E. E., VanLanduyt, L. M., \& Petruzzello, S. J. (2000). Walking in (affective) circles: Can short walks enhance affect? Journal of Behavioral Medicine, 23, 245-275. doi:10.1023/A:1005558025163

Fox, K. R. (2000). Self-esteem, self-perceptions and exercise. International Journal of Sport Psychology, 31, 228-240.

Friedli, L., \& Dardis, C. (2002). Not all in the mind: Mental health service user perspectives on physical health. Journal of Mental Health Promotion, 1, 36-46.

Hippisley-Cox, J. (1998). Depression as a risk factor for ischaemic heart disease in men: Population based case control study. British Medical Journal, 316, 1714-1719. doi:10.1136/bmj.316.7146.1714

Hotopf, M. (2002). The pragmatic randomised controlled trial. Advances in Psychiatric Treatment, 8, 326-333. doi:10.1192/apt.8.5.326

Kubitz, K. A., Landers, D. M., Petruzzello, S. J., \& Han, M. (1996). The effects of acute and chronic exercise on sleep: A metaanalytic review. Sports Medicine, 21, 277-291. doi:10.2165/00007256-199621040-00004

Lacey, A., \& Lacey, L. D. (2001). Framework analysis. Qualitative data analysis. UK: Trent Focus for Research and Development in Primary Care.

Lawlor, D. A., \& Hopker, S. W. (2001). The effectiveness of exercise as an intervention in the management of depression: Systematic review and meta-regression analysis of randomised controlled trials. British Medical Journal, 322, 1-8. doi:10.1136/bmj.322.7289.763

McGeorge, S. (2004). Couch kids: The continuing epidemic. London: British Heart Foundation. 
Mead, G. E., Morley, W., Campbell, P., Greig, C. A., McMurdo, M., \& Lawlor, D. A. (2009). Exercise for depression (review). Cochrane Database of Systematic Reviews, 3, Article ID: CD004366. doi:10.1002/14651858.CD004366.pub4

Mental Health Foundation (2004). Up and running: Exercise therapy and the treatment of mild or moderate depression in primary care. London: Mental Health Foundation.

Mental Health Foundation (2006). Feeding minds. London: Mental Health Foundation.

Morgan, W. P. (2001). Prescription of Physical activity: A paradigm shift. Quest, 53, 366-382. doi:10.1080/00336297.2001.10491754

Mutrie, N. (2002). Healthy body, healthy mind? The Psychologist, 15, 412-413.

Nocon, A. (2004). Equal treatment: Closing the gap. London: Disability Rights Commission.

Oakley, A., Strange, V., Bonell, C., Allen, E., \& Stephenson, J. (2006). Process evaluation in randomised controlled trials of complex interventions. British Medical Journal, 332, 413-416. doi:10.1136/bmj.332.7538.413

Ostir, G. V., Markides, K. S., Peek, M. K., \& Goodwin, J. S. (2001). The association between emotional well-being and the incidence of stroke in older adults. Psychosomatic Medicine, 63, 210-215.

Owen, S., \& Khalil, E. (2006). Meeting the physical health needs of adults with serious and enduring mental illness in community settings. UK: The University of Nottingham.

Paffenberger, R., Lee, I., \& Leung, R. (1994). Physical activity and personal characteristics associated with depression and suicide in American college men. Acta Psychiatrica Scandinavica, 377, 16-22. doi:10.1111/j.1600-0447.1994.tb05796.x
Phelan, M., Stradins, L., \& Morrison, S. (2001). Physical health of people with severe mental illness. British Medical Journal, 322, 443444. doi:10.1136/bmj.322.7284.443

Richardson, C. R., Faulkner, G., McDevitt, J., Skrinar, G. S., Hutchinson, D. S., \& Piette, J. D. (2005). Integrating physical activity into mental health services for persons with serious mental illness. Psychiatric Services, 56, 324-331. doi:10.1176/appi.ps.56.3.324

Robson, D., \& Gray, R. (2007). Serious mental illness and physical health problems: A discussion paper. International Journal of Nursing Studies, 44, 457-466. doi:10.1016/i.ijnurstu.2006.07.013

Scully, D., Kremer, J., Meade, M., Graham, R., \& Dudgeon, K. (1998). Physical exercise and psychological well-being: A critical review. British Journal of Sports Medicine, 32, 111-120. doi:10.1136/bjsm.32.2.111

Seymour, L. (2003). Not all in the mind: The physical health of mental health service users. Radical mentalities briefing paper 2. London: Mentality.

Sherrill, D. L., Kotchou, K., \& Quan, S. F. (1998). Association of physical activity and human sleep disorders. Archives of Internal Medicine, 158, 1894-1898. doi:10.1001/archinte.158.17.1894

Thompson, W. G. (1994). Exercise and health: Fact or hype? Southern Medical Journal, 87, 567-574.

Turner, J., \& Kelly, B. (2000). Emotional dimensions of chronic disease. British Medical Journal, 172, 124-128.

WHO (2007). URL (last checked February 2012). http://www.who.int/mediacentre/factsheets/fs220/en/

Youngstedt, S. D., O’Conno, P. J., \& Dishman, R. K. (1997). The effects of acute exercise on sleep: A quantitative synthesis. Sleep, 20, 203-214. 